\title{
Protein dynamics and the allosteric transitions of pentameric receptor channels
}

\author{
Jean-Pierre Changeux
}

Received: 25 August 2014 / Accepted: 13 November 2014 / Published online: 29 November 2014

(C) The Author(s) 2014. This article is published with open access at Springerlink.com

\begin{abstract}
The recent application of molecular dynamics (MD) methodology to investigate the allosteric transitions of the acetylcholine receptor and its prokaryotic and eukaryotic pentameric homologs has yielded new insights into the mechanisms of signal transduction by these receptors. Combined with available data on X-ray structures, MD techniques enable description of the dynamics of the conformational change at the atomic level, intra-molecular propagation of this signal transduction mechanism as a concerted stepwise process at physiological timescales and the control of this process by allosteric modulators, thereby offering new perspectives for drug design.
\end{abstract}

Keywords Allosteric interactions - Acetylcholine receptor . Molecular dynamics $\cdot$ Conformational changes

\section{Definition of allosteric interactions: importance of molecular dynamics}

We have recently celebrated the "50th anniversary of allostery", and the concept is alive and well. Allosteric interactions between proteins and their regulatory ligands were initially defined as indirect interactions between topographically distinct sites that are mediated by a discrete reversible alteration

J.-P. Changeux $(\bowtie)$

UMR 3571 CNRS, Institut Pasteur, 25 rue du Docteur Roux,

75015 Paris, France

e-mail: changeux@noos.fr

J.-P. Changeux

Collège de France, 11 Place Marcelin Berthelot, 75005 Paris, France

J.-P. Changeux

Kavli Brain-Mind Institute University of California, San Diego, CA, USA of the molecular structure of the protein - and this definition is still valid (for review, Changeux 2013a). The concept was first proposed in 1961 to account for the feedback inhibitory mechanism mediated by the first enzyme of bacterial biosynthetic pathways, in which the feedback inhibitor is not a steric analog of the substrate (Changeux 1961; Monod and Jacob 1961; Gerhart and Pardee 1962). It was expanded in 1963 (Monod et al. 1963) to explain the properties of regulatory proteins in general, including Perutz's structural data on hemoglobin, in the framework of Koshland's (1959) "induced fit" mechanism, according to which the ligand "instructs" rather than "selects" the protein conformational change.

In 1965, attention focused on the observation that, in many regulatory proteins, in addition to, and possibly as part of, the signal transduction mechanism, substrates and regulatory ligands interact in a cooperative manner. It was also noted that all of these interactions may be simultaneously uncoupled by a variety of chemical or physical treatments (Changeux 1961; Gerhart and Pardee 1962). These observations point to a global mechanism at the protein level that makes these regulatory enzymes function as "molecular switches" (Monod et al. 1965; for review, Changeux 2012a, 2013a,b).

To explain the particular protein design involved, a structural hypothesis was proposed where the cooperativity observed between the multiple binding sites for the substrate and regulatory ligand relies on the cooperative organization of the protein into "oligomers" comprising a small number of repeated units and possessing at least one axis of symmetry (Monod et al. 1965). A second critical assumption was that, unlike in the induced-fit model, the regulatory oligomers naturally exist in the absence of the ligand in at least two discrete conformations, the $\mathrm{R}$ state (for relaxed) and the $\mathrm{T}$ state (for constrained), which are in thermodynamic equilibrium. These states differ, in particular, in their tertiary 
distribution and/or inter-subunit bond energy (quaternary constraint). Ligands would then shift the conformational equilibrium by stabilizing the oligomer conformation for which they have the highest affinity, thus mediating signal transduction. Substrate and activators would stabilize the $\mathrm{R}$ state, inhibitors the $\mathrm{T}$ state. The model, termed the Monod-Wyman-Changeux (MWC) model (Monod et al. 1965), assumed that the conformational transition occurs simultaneously for all subunits: it is "concerted" and conserves the oligomer symmetry. Shortly thereafter, in 1966, Koshland et al. proposed a sequential induced-fit mechanism of allosteric transition, referred to as the Koshland-Nemethy-Filmer (KNF) model, which involved a progressive conformational change with ligand binding that excludes any conformational change of the protein in the absence of the ligand.

Abundant studies carried out with a large diversity of regulatory proteins, including neurotransmitter receptors (Changeux 2013a), have lent support to, and further extended, the MWC model, emphasizing in particular "population shifts" within the energy landscape formalism (see Cui and Karplus 2008 ; Itoh and Sasai 2010; Changeux 2012a, 2013a; Terada et al. 2013; Motlagh et al. 2014; Tsai 2014). Importantly, both the MWC and KNF models formulate a static (end-point) equilibrium picture of the allosteric transition. To achieve progress toward the dynamic nature of the phenomenon, complementary and timeresolved analyses, such as molecular dynamics and novel technologies, were needed. As stated by Cui and Karplus (2008), inclusion of atomic fluctuations opens the way to a more sophisticated and accurate interpretation of protein activity that is essential for understanding the mechanism of allosteric interactions. In this review, I shall examine this issue with the nicotinic acetylcholine receptor (nAChR), a neurotransmitter-gated ion channel, which has served in past decades as a privileged model of regulatory protein engaged in intercellular communication in the nervous system. On the basis of recently available crystallographic data, molecular dynamics models of the signal transduction process they mediate have been elaborated and compared with the in vivo physiological data.

\section{The concept of pharmacological receptor, the identification of the nicotinic receptor and the ionic response to acetylcholine}

Ever since Claude Bernard's pioneering work on the effect of curare, the chemistry of intercellular communications has relied on the concept of the pharmacological "receptor" laid down by the English pharmacologist John Newport Langley (1905). It took however 65 years to chemically identifythrough research involving the fish electric organ and a snake venom toxin - the first neurotransmitter receptor, the nicotinic receptor (nAChR) from the neuromuscular junction (Changeux et al. 1970; Miledi et al. 1971 ; Karlin 1993; for review, Changeux 2012b). nAChRs are involved in many brain processes and diseases, such as attention, learning and memory, access to consciousness, nicotine addiction and Alzheimer and Parkinson diseases (for review, Changeux 2006, 2010). Understanding the functional organization and dynamics of these receptors at the atomic level is thus of considerable interest, both in itself and for the development of new therapeutics.

nAChRs are integral allosteric membrane proteins with a molecular mass of approximately $290 \mathrm{kDa}$ that form oligomers comprising five identical or homologous subunits symmetrically arranged around a central ion channel, with a fivefold symmetry axis perpendicular to the membrane (for review, Changeux and Edelstein 2005) (Fig. 1).The primary structure of each subunit consists of a large hydrophilic amino-terminal extracellular (EC) domain, a transmembrane (TM) domain comprising four hydrophobic segments (M1M4) and a variable hydrophilic cytoplasmic or intracellular domain. There are two to five ACh binding sites within the EC domain located at the boundary between subunits. These ACh binding sites are far apart (approx. $60 \AA$ ) but still functionally linked to a single cationic ion channel located on the axis of symmetry of the TM domain and delineated by the M2 $\alpha$ helix (Fig. 1). The interaction between neurotransmitter site and ion channel is thus typically "allosteric." The EC and TM additionally carry several allosteric modulatory sites for natural (e.g. $\mathrm{Ca}^{++}$, lipids) and synthetic (e.g. ivermectin) ligands. Therefore, $n A C h R s$ possess the structural elements required to convert a chemical signal, typically a local increase in extracellular ACh concentration, into an electrical signal generated by the opening of the ion channel. Over the years the nAChR has become the "founding father" of the broader superfamily of pentameric receptors which includes the 5hydroxytryptamine receptor (5HT3R), the inhibitory anionselective $\gamma$-aminobutyric acid type $\mathrm{A}\left(\mathrm{GABA}_{\mathrm{A}}\right)$ and glycine receptors and the invertebrate glutamate-gated chloride channel (GluCl) (Changeux 2012b).

An important outcome of Langley's receptor theory (1905) was the development of electrophysiological recordings aimed at understanding the ionic response of receptors to neurotransmitters (Katz 1966) with the important addition of the time dimension missing in the biochemical-structural approach at the time. At the neuromuscular junction, the postsynaptic potential elicited by either electrical stimulation of the nerve ending or iontophoretic application of ACh has a fast $(<0.2 \mathrm{~ms})$ signal rise time and a signal decay time of a few milliseconds. The local concentration of ACh transiently rises $(<1 \mathrm{~ms})$ to $3 \times 10^{-4} \mathrm{M}$ over a background release of $10^{-8} \mathrm{M}$ (Katz and Miledi 1973, 1977; Kuffler and Yoshikami 1975). 


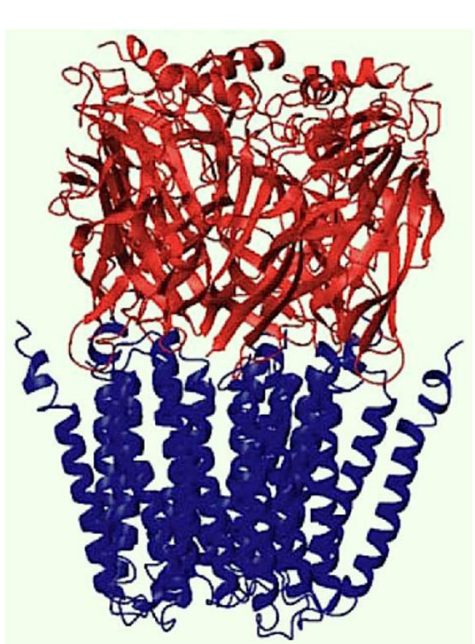

Fig. 1 Left Model of the $\alpha 7$ nicotinic acetylcholine receptor (nAChR) elaborated by Taly et al. (2005) from the X-ray crystal structure of the snail acetylcholine binding protein, a homolog of the extracellular domain (Brejc et al. 2001) and the lower resolution cryo-electron microscopy data of Torpedo nAChR (Unwin 2005) for the membrane domain. From Taly et al. (2005). Right Crystal structure of a prokaryotic homolog of the

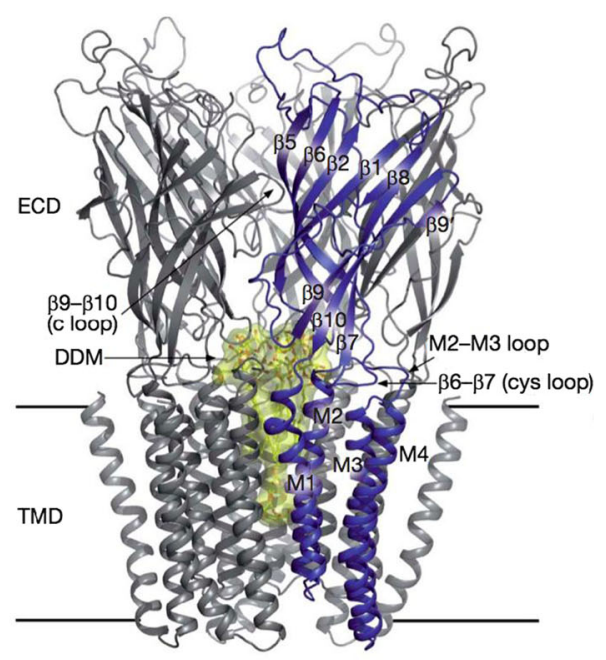

nAChR from Gloeobacter violaceus [G. violaceus ligand-gated ion channel (GLIC)] in its open-channel conformation (Bocquet et al. 2009). ECD Extracellular domain, $T M D$ transmembrane domain of four transmembrane $\alpha$-helices $(M 1-M 4)$ per subunit, DDM detergent dodecyl maltoside-blocked ion channel (yellow). The homology between eukaryotic and prokaryotic receptors is remarkable. From Bocquet et al (2009)
These data were interpreted in terms of the then available models of enzyme kinetics, in particular acetylcholine esterase (Augustinsson 1948, 1950), assuming a two-step process which consisted of the formation of the receptorACh complex followed by opening of the channel (Del Castillo and Katz 1957). This model was consistent with Koshland's induced-fit mechanism (1959):

$\mathrm{R}+\mathrm{A}<-->\mathrm{RA}<-->\mathrm{R} * \mathrm{~A}($ open $)$.

The application of patch-clamp recording techniques revealed that the cellular postsynaptic response can be reduced to the collective opening of separate molecular channels, with each individual opening having a square shape with a rise time in the microsecond range and a mean open time of a few milliseconds (Neher and Sakmann 1976). These values set the time-range for ongoing molecular dynamics studies (see below). Langley (1905) had already noticed that prolonged application of the agonist nicotine blocks receptor responses, resulting in desensitization of the receptor. To fit the electrophysiological data then available, Katz and Thesleff (1957) proposed that ACh slowly (on a $10 \mathrm{~ms}$ to $1 \mathrm{~s}$ timescale) stabilizes a new high-affinity closed ("refractory") state of the receptor which, unlike the "effective" excitable state, would pre-exist ligand binding. Subsequent electrophysiological and biochemical studies with nAChR-rich "excitable" membrane fragments (Kasai and Changeux 1971; Cohen et al. 1972) and a fluorescent analog of acetylcholine (dansyl-C6-choline) enabled researchers to follow directly in vitro the binding kinetics of a nicotinic ligand and its conformational and ionic consequences without using in vivo electrophysiological recordings (Heidmann and Changeux 1979a, b, 1980; Heidmann et al. 1980, see also Neubig and Cohen 1980; Neubig et al. 1982 with radioactive ligands). Extensive kinetic analyses with an adequate rapid mixing apparatus (2.5-ms dead time) resulted in the first experimental in vitro demonstration in the millisecond range of the allosteric transitions of the receptor protein's multiple conformational states: (1) a resting closed-channel $\mathrm{R}$ state stabilized by nicotinic antagonists; (2) an active, fast, open-channel A state with a low affinity for $\mathrm{ACh}$ and nicotinic agonists (kDa ACh: approx.50-100 $\mu \mathrm{M}$ ); (3) at least a fast I and a slow D desensitized, refractory state, with higher affinities for agonists (but also for antagonists) [(kDa of I for ACh: approx.1 $\mu \mathrm{M}$; $\mathrm{kDa}$ of D for ACh: approx. 3-5 nM] (Heidmann and Changeux 1980; see Edelstein et al. 1996). In contrast to a widespread opinion among pharmacologists, the highest affinity states do not correspond to the active functional state of the receptor-quite the contrary is true.

The scheme presented below (Changeux 1990) illustrates the interconversion between the four different states. These states are postulated to occur spontaneously in the absence of ligands. Orthosteric and allosteric (see chapter 6 from Changeux 1990) ligands, binding differentially and selectively, stabilize the state(s) to which each ligand interacts with the highest affinity and, consequently, in the case of agonists (here $\mathrm{ACh}$ ), mediate signal tranduction. Competitive blockers (CB) channel blockers (NCB) and/or allosteric modulators (AM) may selectively stabilize any of the states at the level 
of sites distinct from the ACh binding site and ion channel (see chapter 6 from Changeux 1990).

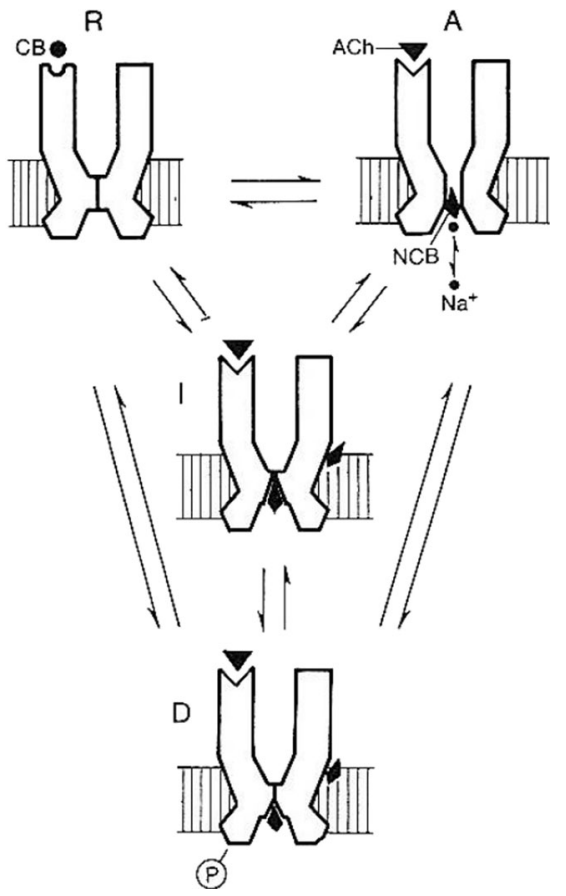

Moreover, a non-negligible fraction (approx. $20 \%$ ) of the receptor resides in the high-affinity D state in the total absence of ligand (Heidmann and Changeux 1979a, b, 1980). In parallel studies, Jackson (1984) observed the spontaneous opening of muscle nAChR in the absence of ACh. Purohit and Auerbach (2013) have recently extended the analysis and elegantly demonstrated that "diliganded and brief unliganded openings are generated by the same essential, global transition", thereby ruling out the induced-fit mechanism and validating the fundamental premises of the MWC model that the basic activation mechanism involves a unique $\mathrm{R} \longrightarrow-\rightarrow \mathrm{A}$ conformational transition that is independent of ligand binding (Auerbach 2012, 2014).

\section{Crystallographic structure of prokaryotic and eukaryotic pentameric receptors}

An important step in the development of the molecular dynamics analysis of pentameric receptors was the availability of high-resolution structural data. Early electron micrographs of nAChR from fish electric organs (Cartaud et al. 1973; Brisson and Unwin 1985a, b) together with the X-ray structure of the homopentameric, water-soluble acetylcholine binding protein (AChBP) from Lymnaea stagnalis (Brejc et al. 2001), which displays significant (approx. $30 \%$ ) sequence homology with the EC domain of the nAChRs and remarkable conservation of the binding site residues, led to the development of atomic models of the full-length nAChR (Unwin 2005, 2013) (see Taly et al. 2014 for discussion). However, the resolution remained low $(>4 \AA)$ due to sample preparation conditions which unfortunately were known to "uncouple" receptor function (Paas et al. 2005; daCosta et al. 2013).

The situation changed dramatically with the discovery in bacteria of DNA sequences homologous to eukaryotic $\mathrm{nAChR}$ (Tasneem et al. 2005) and the subsequent cloning and expression in eukaryotic cells of one of these sequences from the photosynthetic bacterium Gloeobacter violaceus (Bocquet et al. 2007). The protein was demonstrated by electrophysiological recordings to behave as a ligand-gated ion channel activated at acidic pHs (Bocquet et al. 2007). Purification and crystallization of the $G$. violaceus ligand-gated ion channel (GLIC) and of a closely related protein led to the resolution of the first X-ray structure of a pentameric ligand-gated ion channel (pLGIC) in a closed-channel state (resolution $3.3 \AA$ ) from Erwinia chrysanthemi (ELIC) (Hilf and Dutzler 2008) and in an open-channel conformation (resolution $2.9 \AA$ ) from G. violaceus (GLIC) (Bocquet et al. 2009; Hilf and Dutzler 2009). The structure of an eukaryotic member of the family, the anionic glutamate receptor from Caenorhabditis elegans (GluCl), was then solved in an open conformation as a complex with the positive allosteric modulator ivermectin, revealing an astonishing structural similarity with the three-dimensional (3D) structure of GLIC (Hibbs and Gouaux 2011). The recent crystallographic structures of the eukaryotic $\mathrm{GABA}_{\mathrm{A}}$ receptor (Miller and Aricescu 2014) and 5 $\mathrm{HT}_{3}$ receptor (Hassaine et al. 2014) confirm a common structural organization of the constituent subunits. The EC domain folds into a highly conserved immunoglobulin-like $\beta$-sandwich and the TM domain consists of four $\alpha$-helices organized as a well-conserved bundle [in agreement with the low-resolution electron microscopy structures of Torpedo nAChR (Unwin 2005)]. The M2 helix lines the channel walls (Giraudat et al. 1986, 1987; Hucho et al. 1986; Imoto et al. 1986, 1988) and is surrounded by a ring of $\alpha$ helices made of M1 and M3. The fourth TM $\alpha$-helix, M4, is the most peripheral helix and interacts extensively with the lipid bilayer (Bocquet et al. 2009). Also, the cytoplasmic domain, absent in prokaryotic receptors, was revealed for the first time in 5HT3 receptors (Hassaine et al. 2014), further extending our structural knowledge of the family. The access to highresolution full X-ray structures of pentameric receptors legitimated a reliable analysis of the dynamics of their conformational change.

\section{Early studies on the molecular dynamics of signal tranduction mediated by pentameric receptors}

Even before high-resolution structural data became accessible, Taly et al. (2005) developed, by comparative analysis, a 3D model of the $\alpha 7$-nAChR on which they performed the first, 
coarse-grained, molecular dynamics simulation of a pLGIC using the method referred to as "normal mode analysis." By approximating the surface of the conformational landscape, the analysis decomposed the receptor protein movements into discrete modes. Among the ten modes with the lowest frequency, the first showed a structural reorganization described as a concerted rotation, in opposite directions, of the upper EC and lower TM domains around the pore axis - a movement referred to as a quaternary twist. The twist affects the structure of the ion channel toward its opening and results in a significant reshaping of the subunits' interfaces which open and close the agonist binding site(s) located at these interfaces. These observations were confirmed and extended with another model of $\alpha 7$-nAChR (Cheng et al. 2006), with the crystal structures of GLIC (Bocquet et al. 2009) and of ELIC (Cheng et al. 2009) and with a 1- $\mu$ s-long all-atom molecular dynamics simulation of GLIC (Nury et al. 2010). In parallel, another computational study (Taly et al. 2006) on nAChR was undertaken, involving pathological mutations associated with congenital myasthenia and autosomal dominant nocturnal frontal lobe epilepsy. These mutations constitutively stabilize the receptor in an active open conformation, even in the absence of agonist. The substituted amino acids were found to be located at interfaces either between subunits or, within a given subunit, between rigid blocks and thus to alter the twisting mode. Taken together, these results support the conclusion that quaternary twisting is a robust structural motion that accompanies the opening of the ion channel and possibly other moves of the channel, such as those occurring during desensitization.

In parallel electrophysiological studies, Auerbach and colleagues (Grosman et al. 2000; Purohit et al. 2007, 2013; Purohit and Auerbach 2013) examined the gating dynamics of muscle nAChR closed-open transition state ensembles (TSE). These authors measured the single-channel opening $\left(k_{\mathrm{o}}\right)$ and closing $\left(k_{\mathrm{c}}\right)$ rate constants of sets of receptor mutants with various side chain substitutions for individual amino acids. For each series of mutants, properties of the TSE could be deduced from $\phi$ (phi), the slope of a $\log -\log$ plot of $k_{\mathrm{o}}$ versus $K_{\mathrm{eq}}\left(k_{\mathrm{o}} / k_{\mathrm{c}}\right)$. The analysis suggests that the overall $\mathrm{nAChR}$ isomerization consists of a well-defined sequence of protein domain motions that generate a propagated, Brownian stepwise process. Two separate regions in the $\alpha$-subunits, namely, transmitter-binding sites and linkers in the membrane domain, have the highest $\phi$ values (i.e. change conformation the earliest), followed by the EC domain, then most of the membrane domain and finally the gate, resulting in channel opening (Purohit et al. 2013). Accordingly, the gating dynamics of muscle nAChR does not proceed as a single-step "rigid" event but through a concerted, step-wise, conformational mechanism that can be investigated by structural analysis and molecular dynamics simulations.

\section{Structural dynamics model of signal tranduction: an emerging model.}

On the basis of the GLIC open state, the ELIC "undefined" closed state and the $\mathrm{GluCl}$ open-channel structure (when bound to the positive allosteric modulator ivermectin), Calimet et al. (2013) carried out extensive all-atom molecular dynamics simulations in the timescale of $0.2-0.5 \mu \mathrm{s}$. Upon removal of ivermectin, the simulated trajectory of $\mathrm{GluCl}$ reveals a stepwise sequence of structural events that couple agonist unbinding from the EC domain to ion-pore closing in the TM domain. The simulation also shows that, in agreement with Taly et al. (2005), a global twisting initiates the closing transition from the open state by facilitating the (un)tilting of the pore-lining helices. The mechanistic scenario emerging from the simulations suggested that receptor twisting contributes to the activation process by "locking" the ion channel in the open-pore form. In addition, a large reorientation or tilting of the extracellular $\beta$-sandwiches in the outward direction further contributes to the allosteric communication between the neurotransmitter-binding site and the ion pore.

The crystal structures of GLIC at both $\mathrm{pH} 7$ (closed) and $\mathrm{pH} 4$ (open) further provided, for the first time, the end-point structures of the gating mechanism in the same pLGIC (Sauguet et al. 2014a) and included a coarse-grained dynamic modeling of the structures (Sauguet et al. 2014a) (Fig. 2). These data revealed the occurrence of a large quaternary twisting upon receptor activation, as well as the occurrence of important tertiary changes on activation, in particular a significant tilting of the M2 helices. Remarkably, the X-ray structures show, in agreement with Calimet et al. (2013), a radial expansion of the EC domain, termed outward tilting or blooming, which reflects a reorientation of the $\beta$-sandwiches (Fig. 3).

The recent data on $\mathrm{GluCl}$ structure in its apo resting conformation compared to that obtained in the presence of the positive allosteric modulator ivermectin appears, to some extent, to be consistent with some of the conformational changes identified with GLIC (Sauguet et al. 2014a): a twist of the EC domain and a quaternary un-blooming ("resembling the closure of a blossom") occuring upon activation (Althoff et al. 2014). However,in the $\mathrm{GluCl}$ structure, functionally relevant tertiary changes, such as the detachment of the inner and outer $\beta$-sheets and the translation of the C-loop observed with GLIC, are not resolved. Also, differences in the global twist and in the detailed mechanism of reorientation of TM helices are noted. Unfortunately, no molecular dynamics data are available on the recent GluCl data (Althoff et al. 2014).

The structure of a new "locally closed" (LC) state of GLIC - which shows a closed pore in a structure that preserves most of the features of the open form (Prevost et al. 2012) - also brings into question the simple correlation between global twisting and the tilting of the pore-lining helices, 
Fig. 2 Compared crystal structures of the closed ( $\mathrm{pH} 7$; left) and open ( $\mathrm{pH} 4$; right) channel states of the receptor from $G$. violaceus (GLIC). The $\mathrm{pH} 7$ state shows a structural variability which is absent in the $\mathrm{pH} 4$ state. Arrows in the right structure illustrate the concerted quaternary motions of twist and bloom occurring during signal transduction. From Sauguet et al. 2014a, Fig. 4A.
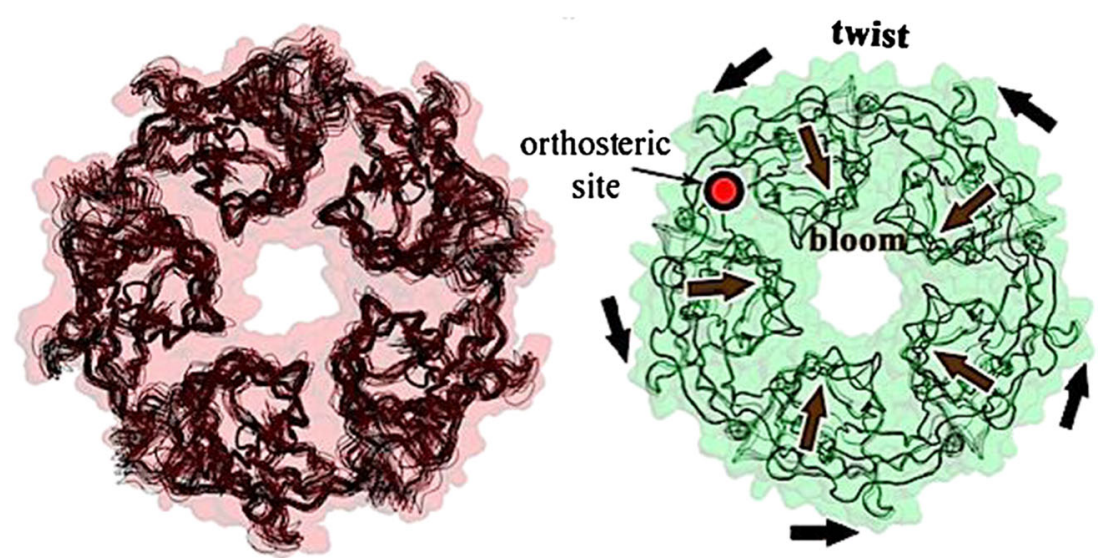

an issue thoroughly discussed in Sauguet et al. (2014a) and Cecchini and Changeux (2014).

Lastly, X-ray analysis of Lymnaea AChBP complexed with a series of 4,6-disubstituted 2-aminopyrimidines exhibiting both positive and negative cooperativity in ligand-binding assays shows that cooperative interactions are associated with a global blooming of the AChBP molecule, yet without a significant twist (Kaczanowska et al. 2014).

Taken together, the most recent molecular dynamics (Calimet et al. 2013; Sauguet et al. 2014a; Taly et al. 2014; Cecchini and Changeux 2014), structural (Sauguet et al. 2014a) and physiological (Purohit et al. 2013) studies converge on a common atomic model of the gating transition (Sauguet et al. 2014a, b; Cecchini and Changeux 2014). According to the model, the "stepwise process" would start from the orthosteric-binding site (loops A, B and C), propagate to the EC/TM interface ( $\beta 1-\beta 2$ loop and Cys loop) via a rigid-body rearrangement of the EC $\beta$-sandwiches and move down to the TM helices (first M2, then M4 and M3) to finally open the gate (Fig. 4). This process would involve two distinct sequential quaternary transitions: a radial concerted contraction or un-blooming of the EC domain, which promotes opening of the ion pore, followed by a global concerted twisting of the receptor to lock the channel in the active, open channel, state.

The data are consistent with single-channel recordings (Zheng and Auerbach 2011; Purohit et al. 2013) and their dynamics on a microsecond to millisecond timescale. They are also consistent with the MWC postulate that the conformational transition is "concerted" and, at the endpoints, conserves the symmetry of the oligomer. Furthermore, in agreement with the conformational selection mechanism, Sauguet et al. (2014a) observed that in some crystal forms of GLIC $\mathrm{pH} 4$, the locally closed and open conformations are found to coexist as discrete entities. Interestingly, the greater fluctuations observed in crystals of GLIC $\mathrm{pH} 7$ prefigured the conformational change toward the open state-as

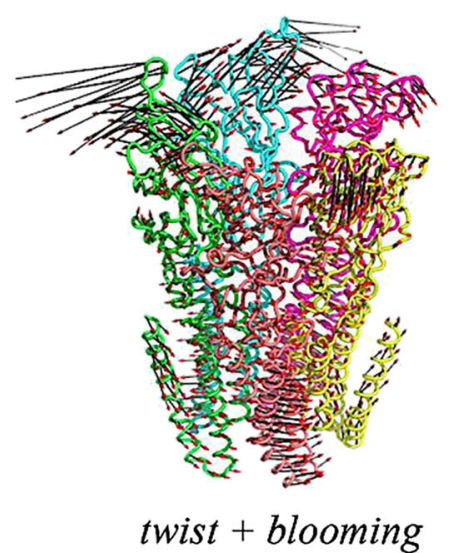

Fig. 3 Analysis of the quaternary motions of the GLIC twist and blooming involved in the allosteric transition linking the ECD and the ion channel. Comparing the resulting profiles between the $\mathrm{pH} 7$ and $\mathrm{pH} 4$ structures highlights the combination of radial and tangential movements that relate them in the course of channel opening and are viewed as

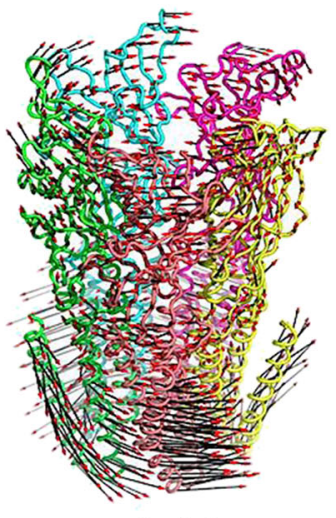

twist

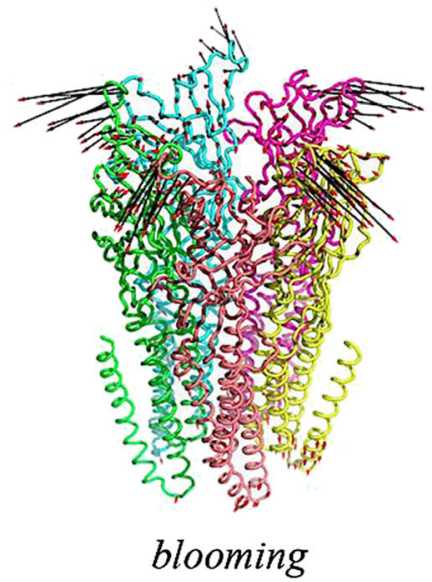

corresponding to two different normal modes: twist and blooming, respectively. Difference vectors $\mathrm{pH} 7$ (closed channel) to $\mathrm{pH} 4$ (open channel). From left to right Twist and blooming; twist; blooming. From Sauguet et al. 2014a, Figure S8b 


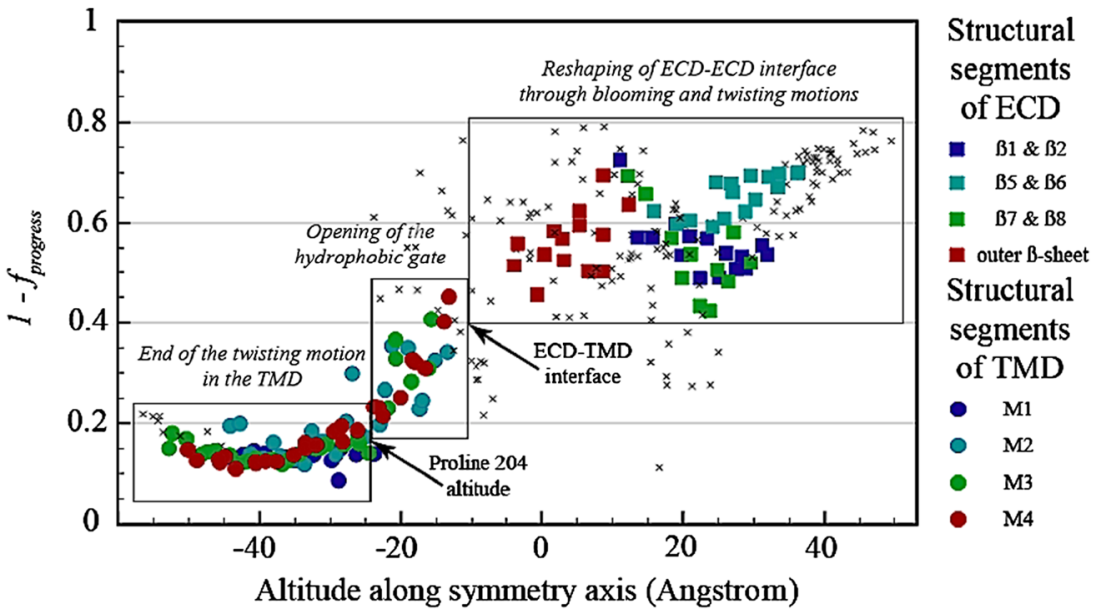

Fig. 4 Coarsed grained molecular dynamics trajectories for the gating of the ion channel of the $G$. violaceus receptor. Opening of the ion channel is from right to left. The iENM web server (http://enm.lobos.nih.gov) was used to generate plausible trajectories between the four closed GLIC $\mathrm{pH}$ 7, the open GLIC pH 4 and the locally closed structures. The trajectories are mapped onto ECD and TMD reaction coordinates to quantify the differential progress of conformational change in these two domains.

if the latter was already "on-path" even under conditions which did not favor its occurrence.

Finally, several fast and slow desensitized I and D states and uncoupled forms of prokaryotic receptors have been identified, and their structures are currently under investigation. For example, the locally closed state (Prevost et al. 2012) might be a fast desensitized I state (Prevost et al. 2013), and the closed state of ELIC - often considered to be a resting state (see Calimet et al. 2013) - might represent a slowly desensitized D one (Velisetty et al. 2012; Sauguet et al. 2014a). The ELIC structure has also been suggested to be in a "refractory" (Gonzalez-Gutierrez et al. 2012)/“uncoupled" state (daCosta and Baenziger 2013) (see Cecchini and Changeux 2014 for discussion).

\section{Allosteric modulation of receptor function: toward a new pharmacology}

Several categories of allosteric sites modulate signal transduction mediated by $\mathrm{nAChR} . \mathrm{Ca}^{2+}$, at millimolar concentrations, potentiates most neuronal nAChRs (Mulle et al. 1992; Vernino et al. 1992) and binds to sites located at the subunit interface of the EC domain, below the ACh site near the TM (Le Novere et al. 2002). In agreement with the MWC model, $\mathrm{Ca}^{2+}$ primarily affects the isomerization constant between the $\mathrm{R}$ and open A conformation (Galzi et al. 1996). A second class of allosteric sites lies within the TM and accommodates pharmacological agents which regulate receptor activity in either a positive (e.g. the antihelminthic ivermectin; Krause et al. 1998) or a negative [e.g. general anesthetics (GAs; for
Residues belonging to structural segments (loops) are displayed with colored symbols (see color code on the right); all other residues are displayed with small crosses. The figure illustrates the stepwise progress of the concerted conformational change: from right to left channel opening process starting at the $\mathrm{ECD}$, from left to right channel closing process starting at the TMD. From Sauguet et al. 2014a, Figure S18c.

review, Nury et al. 2011) or ethanol (Sauguet et al. 2013)]. With mammalian $\mathrm{GABA}_{\mathrm{A}}$ receptors, early studies by photoaffinity labeling with a derivative of the GA etomidate identified sites located both between and within subunits, in the TM domain (for review, Olsen 2014). Amazingly, GAs such as propofol and desflurane negatively modulate the response of the prokaryotic GLIC receptor. The X-ray structure of a GLIC-GA complex reveals that GAs bind to a common site within the upper part of the TM of each subunit inside a cavity accessible to phospholipids from the lipid bilayer (Nury et al. 2011). The entrance to this cavity is obstructed by a lipid alkyl chain that competes with propofol binding. Lipids, free fatty acids and steroids are known to allosterically modulate pLGICs and are thus likely candidates as endogenous ligands for the GA sites (Nury et al. 2011; Sauguet et al. 2013). Ivermectin, which positively modulates $\mathrm{GluCl}$, binds to $\mathrm{GluCl}$ crystals at subunit interfaces between M3 and M1 (Hibbs and Gouaux 2011) and also competes with phospholipids (Althoff et al. 2014). It would appear that ivermectin is homologous to many important modulators of pentameric receptors, such as alcohols, anticonvulsants, anesthetics and diuretics (Sauguet et al. 2014b).

Molecular dynamic studies (Calimet et al. 2013; Sauguet et al. 2014a, b, Cecchini and Changeux 2014) of GluCl, and the crystal structures of GLIC pH 4 and pH 7 unambiguously show that the gating transitions involve a significant restructuring of the subunits' interfaces. This restructuring includes a large contraction of the orthosteric sites in the RA transition and a major change of the allosteric modulatory sites: widening of the homolog of the $\mathrm{Ca}^{2+}$ site pocket in the $\mathrm{pH} 7 \mathrm{R}$ state and stabilization by positive allosteric modulators 
(ivermectin) of the untwisted (open pore) configuration of the TM site (Sauguet et al 2014a; Althoff et al 2014).

From a drug design perspective, the model suggests as logical targets the orthosteric and allosteric sites present on these defined conformation(s) - rather than a single rigid binding site (Changeux 2012a, 2013a; Sauguet et al. 2014b). It thus makes possible to selectively generate agonistic versus antagonistic-orthosteric or allosteric modulatory-ligands. The model also predicts that by altering the unliganded equilibrium between discrete conformational states, gene mutations may cause constitutive receptor activation (or inhibition) with important pathological consequences (Changeux and Edelstein 2005; Taly et al. 2006).

\section{Conclusions: receptor dynamics and higher brain functions}

The introduction of molecular dynamics approaches in the analysis of the allosteric transition in pLGIC has led to a description, at the atomic level, of the conformational change mediating signal transduction and its intramolecular propagation as a concerted stepwise process at physiological timescales. It has also catalyzed understanding of the signal transduction mechanism mediated by ion channels (for review, Christopoulos et al. 2014) and other classes of membrane receptors, such as the $\mathrm{G}$ proteincoupled receptors (for review Bouvier 2013), the tyrosine kinase receptors or, even, the nuclear receptors (for review, Changeux 2012a, 2013b; Christopoulos et al. 2014).

The finding that some of the basic building blocks of the brain, such as the pentameric receptors, have not markedly changed for 3 billion years raises an interesting issue. The dynamics of our brain processes, including our mental ones, are constrained by the timescale of conformational transitions that originated in bacteria. This constraint possibly explains why our brain, which processes propagating signals below the speed of sound, looks so slow compared to computers operating at the speed of light.

These investigations further document and enrich what may be referred to as a "chemical theory of higher brain functions" (Changeux 1983, 2013b). Within this framework, would our ultimate mental processes rest upon the biochemical world of allosteric transitions that mediate interneuronal communications across the multiple levels of organization that span the human brain?

Acknowledgments JPC thanks the Woods Hole Marine Biological Laboratory, Mass. USA, where this review was written and Drs. Paul De Weere, Henri Korn, Frederic Poitevin and Ludovic Sauguet for constructive remarks and suggestions on the manuscript. JPC gratefully acknowledges the contributions to the work presented in this review of many collaborators and colleagues throughout the past decades in particular, recently, Marco Cechini.

Conflict of interest None.
Human \& animal studies This article does not contain any studies with human or animal subjects performed by the author, with the exception of those carried out on electric fish.

Open Access This article is distributed under the terms of the Creative Commons Attribution License which permits any use, distribution, and reproduction in any medium, provided the original author(s) and the source are credited.

\section{References}

Althoff T, Hibbs RE, Banerjee S, Gouaux E (2014) X-ray structures of $\mathrm{GluCl}$ in apo states reveal a gating mechanism of Cys-loop receptors. Nature 512:333-337

Auerbach A (2012) Thinking in cycles: MWC is a good model for acetylcholine receptor-channels. J Physiol 590:93-98

\section{A brilliant demonstration of the applicability of the MWC model to the electrophysiological respone of muscle nicotinic receptor to acetylcholine.}

Auerbach A (2014) Agonist activation of muscle nicotinic acetylcholine receptors. Neuropharmacology (accepted for publication)

Augustinsson KB (1948) Cholinesterase: a study in comparative enzymology. Acta Physiol Scand 182[Suppl]:50-53

Augustinsson KB (1950) Acetylcholine esterase and cholinesterase. In: The enzymes. Academic press, New York, pp 443-472

Bocquet N, Prado de Carvalho L, Cartaud J, Neyton J, Le Poupon C, Taly A, Grutter T, Changeux JP, Corringer PJ (2007) A prokaryotic proton-gated ion channel from the nicotinic acetylcholine receptor family. Nature 445:116-119

\section{The first X-ray structure of a pentameric ligand-gated ion} channel in an open conformation

Bocquet N, Nury H, Baaden M, Le Poupon C, Changeux JP, Delarue M, Corringer PJ (2009) X-ray structure of a pentameric ligand-gated ion channel in an apparently open conformation. Nature 457:111-114

Bouvier M (2013) Unraveling the structural basis of GPCR activation and inactivation. Nat Struct Mol Biol 2013(20):539-541

Brejc K, van Dijk WJ, Klaassen RV, Schuurmans M, van Der Oost J, Smit AB, Sixma TK (2001) Crystal structure of an ACh-binding protein reveals the ligand-binding domain of nicotinic receptors. Nature 411:269-276

Brisson A, Unwin PN (1985a) Tubular crystals of acetylcholine receptor. J Cell Biol 99:1202-1211

Brisson A, Unwin PN (1985b) Quaternary structure of the acetylcholine receptor. Nature 315:474-477

Calimet N, Simoes M, Changeux JP, Karplus M, Taly A, Cecchini M (2013) A gating mechanism of pentameric ligand-gated ion channels. Proc Natl Acad Sci USA 110:E3987-E3996. doi:10.1073/ pnas. 1313785110

An extensive all-atom molecular dynamics simulation of the allosteric transition for gating of pentameric receptors.

Cartaud J, Benedetti EL, Cohen JB, Meunier JC, Changeux JP (1973) Presence of a lattice structure in membrane fragments rich in 
nicotinic receptor protein from the electric organ of Torpedo marmorata. FEBS Lett 33:109-113

Cecchini M, Changeux JP (2014) The nicotinic acetylcholine receptor and its prokaryotic homologues: structure, conformational transitions \& allosteric modulation. Neuropharmacology (in press)

Changeux JP (1961) The feedback control mechanisms of biosynthetic Lthreonine deaminase by L-isoleucine. Cold Spring Harb Symp Quant Biol 26:313-318

Changeux JP (1983) L'Homme neuronal. Paris, Fayard (Translated by Laurence Garey as Neuronal Man (1985); Pantheon, New York

Changeux JP (1990) Functional architecture and dynamics of the nicotinic acetylcholine receptor: an allosretic ligand-gated ion channel . In: Changeux JP, Llinas R, Purves D, Bloom F (eds) Fidia resarch foundation neuroscience award lectures, vol 4. Raven press, NewYork, p 17-168

Changeux JP (2006) The Ferrier Lecture 1998. The molecular biology of consciousness investigated with genetically modified mice Philos Trans R Soc Lond B Biol Sci 361:2239-2259

Changeux JP (2010) Nicotine addiction and nicotinic receptors: lessons from genetically modified mice. Nat Rev Neurosci 11:389-401

Changeux JP (2012a) Allostery and the Monod-Wyman-Changeux model after 50 years. Annu Rev Biophys 41:103-133

Changeux JP (2012b) (2012b) The nicotinic acetylcholine receptor: the founding father of the pentameric ligand-gated ion channel superfamily. J Biol Chem 287:40207-40215

Changeux JP (2013a) 50 years of allosteric interactions: the twists and turns of the models. Nat Rev Mol Cell Biol 14:819-829

\section{An update of the theory of allosteric interactions after 50 years.}

Changeux JP (2013b) The concept of allosteric interaction and its consequences for the chemistry of the brain. J Biol Chem 288:2696926986

Changeux JP, Edelstein SJ (2005) Nicotinic acetylcholine receptors. New York, Odile Jacob

Changeux JP, Kasai M, Lee CY (1970) Use of a snake venom toxin to characterize the cholinergic receptor protein. Proc Natl Acad Sci USA 67:1241-1247

Cheng X, Ivanov I, Wang H, Sine SM, McCammon JA (2009) (2009) Molecular-dynamics simulations of ELIC a prokaryotic homologue of the nicotinic acetylcholine receptor. Biophys J 96:4502-4513

Cheng X, Lu B, Grant B, Law RJ, McCammon JA (2006) Channel opening motion of alpha7 nicotinic acetylcholine receptor as suggested by normal mode analysis. J Mol Biol 355:310-324

Cohen JB, Weber M, Huchet M, Changeux JP (1972) Purification from Torpedo marmorata electric tissue of membrane fragments particularly rich in cholinergic receptor protein. FEBS Lett 26:43-47

Christopoulos A, Changeux JP, Catterall WA, Fabbro D, Burris TP, Cidlowski JA, Olsen RW, Peters JA, Neubig RR, Pin JP, Sexton PM, Kenakin TP, Ehlert FJ, Spedding M, Langmead CJ (2014) International Union of Basic and Clinical Pharmacology. XC. Multisite pharmacology: recommendations for the nomenclature of receptor allosterism and allosteric ligands. Pharmacol Rev 66(4):918-947. doi:10.1124/pr.114. 008862

Cui Q, Karplus M (2008) Allostery and cooperativity revisited. Protein Sci 17:1295-1307

daCosta CJ, Baenziger JE (2013) Gating of pentameric ligand-gated ion channels: structural insights and ambiguities. Structure 21:1271-1283

daCosta CJ, Dey L, Therien JP, Baenziger JE (2013) A distinct mechanism for activating uncoupled nicotinic acetylcholine receptors. Nat Chem Biol 9:701-707
Del Castillo J, Katz B (1957) Interaction at end-plate receptors between different choline derivatives. Proc R Soc Lond B 146:369-381

Edelstein SJ, Schaad O, Henry E, Bertrand D, Changeux JP (1996) A kinetic mechanism for nicotinic acetylcholine receptors based on multiple allosteric transitions. Biol Cybern 75:361-379

Galzi JL, Bertrand S, Corringer PJ, Changeux JP, Bertrand D (1996) Identification of calcium binding sites that regulate potentiation of a neuronal nicotinic acetylcholine receptor. EMBO J 15:5824-5832

Gerhart JC, Pardee AB (1962) The enzymology of control by feedback inhibition. J Biol Chem 237:891-896

Giraudat J, Dennis M, Heidmann T, Chang JY, Changeux JP (1986) Structure of the high-affinity binding site for noncompetitive blockers of the acetylcholine receptor: serine- 262 of the delta subunit is labeled by $[3 \mathrm{H}]$ chlorpromazine. Proc Natl Acad Sci USA 83: 2719-2723

Giraudat J, Dennis M, Heidmann T, Haumont PY, Lederer F, Changeux JP (1987) Structure of the high-affinity binding site for noncompetitive blockers of the acetylcholine receptor: $[3 \mathrm{H}]$ chlorpromazine labels homologous residues in the beta and delta chains. Biochemistry 26:2410-2418

Gonzalez-Gutierrez G, Lukk T, Agarwal V, Papke D, Nair SK, Grosman C (2012) Mutations that stabilize the open state of the Erwinia chrisanthemi ligand-gated ion channel fail to change the conformation of the pore domain in crystals. Proc Natl Acad Sci USA 109: 6331-6336

Grosman C, Zhou M, Auerbach A (2000) Mapping the conformational wave of acetylcholine receptor channel gating. Nature 403:773

Hassaine G, Deluz C, Grasso L, Wyss R, Tol M, Hovius R, Graff A, Stahlberg H, Desmyter A, Moreau C, Li XD, Poitevin F, Vogel H, Nury H (2014) X-ray structure of the mouse serotonin 5-HT3 receptor. Nature 512: 276-281. doi:10.1038/ nature 13552

Heidmann T, Changeux JP (1979a) Fast kinetic studies on the interaction of a fluorescent agonist with the membrane-bound acetylcholine receptor from Torpedo marmorata. Eur J Biochem 94:255-279

Heidmann T, Changeux JP (1979b) Fast kinetic studies on the allosteric interactions between acetylcholine receptor and local anesthetic binding sites. Eur J Biochem 94:281-296

Heidmann T, Changeux JP (1980) Interaction of a fluorescent agonist with the membrane-bound acetylcholine receptor from Torpedo marmorata in the millisecond time range: resolution of an "intermediate" conformational transition and evidence for positive cooperative effects. Biochem Biophys Res Commun 97:889-896

Heidmann T, Bernhardt J, Neumann E, Changeux JP (1980) Rapid kinetics of agonist binding and permeability response analyzed in parallel on acetylcholine receptor rich membranes from Torpedo marmorata. Biochemistry 22:5452-5459

Hibbs RE, Gouaux E (2011) Principles of activation and permeation in an anion-selective Cys-loop receptor. Nature 474:54-60

Hilf RJ, Dutzler R (2008) X-ray structure of a prokaryotic pentameric ligand-gated ion channel. Nature 452:375-379

\section{The first X-ray structure of a pentameric ligand-gated ion channel in a closed conformation}

Hilf RJ, Dutzler R (2009) Structure of a potentially open state of a protonactivated pentameric ligand-gated ion channel. Nature 457:115-118

Hucho F, Oberthür W, Lottspeich F (1986) The ion channel of the nicotinic acetylcholine receptor is formed by the homologous helices M II of the receptor subunits. FEBS Lett 205:137-142

Imoto K, Busch C, Sakmann B, Mishina M, Konno T, Nakai J, Bujo H, Mori Y, Fukuda K, Numa S (1988) Rings of negatively charged amino acids determine the acetylcholine receptor channel conductance. Nature 335:645-648 
Imoto K, Methfessel C, Sakmann B, Mishina M, Mori Y, Konno T, Fukuda K, Kurasaki M, Bujo H, Fujita Y et al (1986) Location of a delta-subunit region determining ion transport through the acetylcholine receptor channel. Nature 324:670-674

Itoh K, Sasai M (2010) Entropic mechanism of large fluctuation in allosteric transition. Proc Natl Acad Sci USA 107:77757780

Jackson MB (1984) Spontaneous openings of the acetylcholine receptor channel. Proc Natl Acad Sci USA 81:3901-3904

Kaczanowska K, Harel M, Radić Z, Changeux JP, Finn MG, Taylor P (2014) Structural basis for cooperative interactions of substituted 2aminopyrimidines with the acetylcholine binding protein. Proc Natl Acad Sci USA 111:10749-10754

Karlin A (1993) Structure of nicotinic acetylcholine receptors. Curr Opin Neurobiol 3:299-309

Kasai M, Changeux JP (1971) In vitro excitation of purified membrane fragments by cholinergic agonists. J Membr Biol 6:1-23; 24-57; 58-80; 81-88

Katz B (1966) Nerve, muscle and synapse. Mc Graw-Hill, New-York

Katz B, Miledi R (1973) The binding of acetylcholine to receptors and its removal from the synaptic cleft. J Physiol 231:549-574

Katz B, Miledi R (1977) Transmitter leakage from motor nerve endings. Proc R Soc Lond B Biol Sci 196:59-72

Katz B, Thesleff S (1957) A study of the desensitization produced by acetylcholine at the motor end-plate. J Physiol 138:63-80

Koshland DE Jr (1959) Enzyme flexibility and enzyme action. J Cell Comp Physiol 54:245-258

Koshland DE Jr, Nemethy G, Filmer D (1966) Comparison of expérimental binding data and theoretical models in proteins containing subunits. Biochemistry 5:365-385

Krause RM, Buisson B, Bertrand S, Corringer PJ, Galzi JL, Changeux JP, Bertrand D (1998) Ivermectin: a positive allosteric effector of the alpha7 neuronal nicotinic acetylcholine receptor. Mol Pharmacol 53: 283-294

Kuffler SW, Yoshikami D (1975) The distribution of acetylcholine sensitivity at the post-synaptic membrane of vertebrate skeletal twitch muscles: iontophoretic mapping in the micron range. J Physiol 244: 703-730

Langley JN (1905) On the reaction of cells and nerve endings to certain poisons, chiefly as regards the reaction of striated muscle to nicotine and to curare. J Physiol 33:374-413

Le Novere N, Grutter T, Changeux J-P (2002) Models of the extracellular domain of the nicotinic receptors and of agonist and $\mathrm{Ca}^{2+}$ binding sites. Proc Natl Acad Sci USA 99:3210-3215

Miledi R, Molinoff P, Potter LT (1971) Isolation of the cholinergic receptor protein of Torpedo electric tissue. Nature 229: 554-557

Miller PS, Aricescu AR (2014) Crystal structure of a human GABAA receptor. Nature 512:270-275 doi:10.1038/nature13293

Monod J, Jacob F (1961) Teleonomic mechanisms in cellular metabolism, growth, and differentiation. Cold Spring Harb Symp Quant Biol 26:389-401

Monod J, Changeux JP, Jacob F (1963) Allosteric proteins and cellular control systems. J Mol Biol 6:306-329

Monod J, Wyman J, Changeux JP (1965) On the nature of allosteric transitions: a plausible model. J Mol Biol 12:88-118

Motlagh HN, Wrabl JO, Li J, Hilser VJ (2014) The ensemble nature of allostery. Nature 508:331-339

Mulle C, Léna C, Changeux JP (1992) Potentiation of nicotinic receptor response by external calcium in rat central neurons. Neuron 8:937945

Neher E, Sakmann B (1976) Single-channel currents recorded from membrane of denervated frog muscle fibres. Nature 260:799-802
Neubig RR, Boyd ND, Cohen JB (1982) Conformations of Torpedo acetylcholine receptor associated with ion transport and desensitization. Biochemistry 21:3460-3467

Neubig RR, Cohen JB (1980) Permeability control by cholinergic receptors in Torpedo postsynaptic membranes: agonist dose-response relations measured at second and millisecond times. Biochemistry 19:2770-2779

Nury H, Poitevin F, Van Renterghem C, Changeux JP, Corringer PJ, Delarue M, Baaden M (2010) One-microsecond molecular dynamics simulation of channel gating in a nicotinic receptor homologue. Proc Natl Acad Sci USA 107:6275-6280

Nury H, Van Renterghem C, Weng Y, Tran A, Baaden M, Dufresne V, Changeux JP, Sonner JM, Delarue M, Corringer PJ (2011) X-ray structures of general anaesthetics bound to a pentameric ligandgated ion channel. Nature 469:428-431

Olsen R (2014) Analysis of c-aminobutyric Acid (GABA) type A receptor subtypes using isosteric and allosteric ligands. Neurochem Res 39:1924-1941

Paas Y, Gibor G, Grailhe R, Savatier-Duclert N, Dufresne V, Sunesen M, de Carvalho LP, Changeux JP, Attali B (2005) Pore conformations and gating mechanism of a Cys-loop receptor. Proc Natl Acad Sci USA 102:15877-15882

Prevost MS, Moraga-Cid G, Van Renterghem C, Edelstein SJ, Changeux JP, Corringer PJ (2013) Intermediate closed state for glycine receptor function revealed by cysteine cross-linking. Proc Natl Acad Sci USA 110:17113-17118

Prevost MS, Sauguet L, Nury H, Van Renterghem C, Huon C, Poitevin F, Baaden M, Delarue M, Corringer PJ (2012) A locally closed conformation of a bacterial pentameric proton-gated ion channel. Nat Struct Mol Biol 19:642-649

Purohit P, Auerbach A (2013) Loop C and the mechanism of acetylcholine receptor-channel gating. J Gen Physiol 141:467-478

Purohit P, Mitra A, Auerbach A (2007) Stepwise mechanism for acetylcholine receptor channel gating. Nature 446:930-933

Purohit PS, Gupta S, Jadey S, Auerbach A (2013) Functional anatomy of an allosteric protein. Nat Commun 4:2984

The authors synthesize the strategy they have used to investigate the dynamics of the "conformational wave" of muscle nicotinic receptor using electrophysiological methods.

Sauguet L, Howard RJ, Malherbe L, Lee US, Corringer PJ, Harris RA, Delarue M (2013) Structural basis for potentiation by alcohols and anaesthetics in a ligand-gated ion channel. Nat Commun 4:1697. doi:10.1038/ncomms 2682

Sauguet L, Shahsavar A, Poitevin F, Huon C, Menny A, Nemecz À, Haouz A, Changeux JP, Corringer PJ, Delarue M (2014a) Crystal structures of a pentameric ligand-gated ion channel provide a mechanism for activation. Proc Natl Acad Sci USA 111:966-971

The first description of the crystal structure of the resting and active conformation obtained with the same pentameric receptor together with a coarse grain model of receptor activation based on these data.

Sauguet L, Shahsavar A, Delarue M (2014b) Crystallographic studies of pharmacological sites in pentameric ligand-gated ion channels. Biochim Biophys Acta. doi: doi: 10.1016/j.bbagen.2014.05.007

Taly A, Corringer PJ, Grutter T, Prado de Carvalho L, Karplus M, Changeux JP (2006) Implications of the quaternary twist allosteric 
model for the physiology and pathology of nicotinic acetylcholine receptors. Proc Natl Acad Sci USA 103:16965-16970

Taly A, Hénin J, Changeux JP, Cecchini M (2014) Allosteric regulation of pentameric ligand-gated ion channels: an emerging mechanistic perspective. Channels 8:1-11

\section{An original prediction of the causes of pathological} mutations on the allosteric transition of the nicotinic receptor based upon molecular dynamics simulations.

Taly A, Delarue M, Grutter T, Nilges M, Le Novere N, Corringer PJ, Changeux JP (2005) Normal mode analysis suggests a quaternary twist model for the nicotinic receptor gating mechanism. Biophys $\mathbf{J}$ 88:3954-3965

\section{An early attempt to investigate the conformational transitions of the nicotinic acetylcholine receptor by molecular dynamics methods.}

Tasneem A, Iyer LM, Jakobsson E, Aravind L (2005) Identification of the prokaryotic ligand-gated ion channels and their implications for the mechanisms and origins of animal Cys-loop ion channels. Genome Biol 6:R4. doi:10.1186/gb-2004-6-1-r4
Terada TP, Terada TP, Kimura T, Sasai M (2013) Entropic mechanism of allosteric communication in conformational transitions of dihydrofolate reductase. J Phys Chem B 117: 12864-12877

Tsai CJ (2014) Nussinov R (2014) A unified view of "how allostery works". PLoS Comput Biol 10(2):e1003394. doi:10.1371/journal. pcbi. 1003394

Unwin N (2005) Refined structure of the nicotinic acetylcholine receptor at $4 \AA$ resolution. J Mol Biol 346:967-989

Unwin N (2013) Nicotinic acetylcholine receptor and the structural basis of neuromuscular transmission: insights from Torpedo postsynaptic membranes. Q Rev Biophys 46:283322

Velisetty P, Chalamalasetti SV, Chakrapani S (2012) Conformational transitions underlying pore opening and desensitization in membrane-embedded Gloeobacter violaceus ligand-gated ion channel (GLIC). J Biol Chem 287:36864-36872

Vernino S, Amador M, Luetje CW, Patrick J, Dani JA (1992) Calcium modulation and high calcium permeability of neuronal nicotinic acetylcholine receptors. Neuron 8:127-134

Zheng W, Auerbach A (2011) Decrypting the sequence of structural events during the gating transition of pentameric ligandgated ion channels based on an interpolated elastic network model. PLoS Comput Biol 7(1):e1001046. doi:10.1371/ journal.pcbi.1001046 